\title{
Morphological Study on the Correlation of Prenatal and Postnatal Development between Mouse Parotid Salivary Gland and Tooth
}

\author{
Soon-Jeong Jeong, Moon-Jin Jeong ${ }^{1, *}$ \\ Department of Dental Hygiene, College of Health Science, Youngsan University, Yangsan 50510, Korea \\ ${ }^{1}$ Department of Oral Histology and Developmental Biology, School of Dentistry, Chosun University, Gwangju 61452, Korea
}

\author{
*Correspondence to: \\ Jeong MJ, \\ Tel: +82-62-230-6895 \\ Fax: +82-62-608-5732 \\ E-mail: mijeong@chosun.ac.kr
}

Received October 17, 2017

Revised December 1, 2017

Accepted December 4, 2017
The purpose of this study was to characterize the prenatal and postnatal development of the mouse parotid salivary gland and tooth, and to investigate the relationship between the developmental timing of the two organs. Development of parotid salivary gland begins on embryonic day 15 (E15), which is the prebud stage; E17 is the initial bud stage; E21 to postnatal day 3 (PN3) is the pseudoglandular stage; PN5 to PN10 is the canalicular stage; and PN21 is the terminal bud stage. At E15, the developing maxillary molar tissue is at the bud stage; at E17, it is at the cap stage; at E21, it is at the early bell stage; PN3 to PN5 comprises the advanced bell stage; at PN10, it is at the crown stage; at PN21, it is at the functional stage. Therefore, unlike the other major salivary glands, the development of mouse parotid salivary gland is completed through a process of prenatal and postnatal morphogenesis and becomes functional at about the same time as the developing tooth. The developmental completion times of the parotid salivary gland and tooth are closely related to the weaning time of animal.

Key Words: Development, Morphogenesis, Mouse, Parotid salivary gland, Tooth

\section{INTRODUCTION}

In the mouse, there are three pairs of major salivary glands, which develop as the result of epithelial-mesenchymal interactions and form at set positions within the mouth. Salivary gland development can be divided into five stages: prebud, initial bud, pseudoglandular, canalicular, and terminal bud (Jaskoll \& Melnick, 1999; Jaskoll et al., 1998; Melnick \& Jaskoll, 2000; Zhou et al., 2010). The major salivary glands are named according to their anatomical location: parotid, sublingual, and submandibular (Amano, 2011; Amano et al., 2012; Saracco \& Crabill, 1993; Williams et al., 1989). The submandibular and sublingual salivary glands are located under the tongue, while the parotid salivary glands are located at the back of the mouth between the upper and lower jaw (Tucker, 2007). Each salivary gland is composed of acini, which are formed by glandular secretory cells, and surrounding myoepithelial cells and ducts, including intercalated and striated ducts, which terminate in the lumen (Amano et al., 2012; Chi, 1996; Melnick \& Jaskoll, 2000). The acini, the secretory portion of the salivary gland, produce and secrete primitive saliva of which there are three types, serous, mucous and mixed saliva depending on the characteristics of the secretory cells (Amano et al., 2012; Chi, 1996). The parotid salivary gland is the largest of the salivary glands, and in the mouse the parotid glands consist of serous acinar cells that secrete an abundance of amylase (Amano et al., 2012; Leith et al., 2014; Tucker, 2007).

Tooth development broadly comprises three stages, the bud stage, cap stage and bell stage and is a continuous process (Antonio, 2008). As a result of interactions between the epithelium and mesenchyme, the epithelial cells differentiate into ameloblasts and the ectomesenchymal cells differentiate into odontoblasts (Maas \& Bei, 1997; Theslef \& Sharpe,

(a) This is an open-access article distributed under the terms of the Creative Commons Attribution Non-Commercial License (http://creativecommons.org/licenses/by-nc/4.0) which permits unrestricted noncommercial use, distribution, and reproduction in any medium, provided the original work is properly cited.

Copyrights (C) 2017 by Korean Society of Microscopy 
1997). Ameloblasts are known to temporally synthesize and secrete protein for enamel formation, while odontoblasts continuously synthesize and secrete protein that forms dentine (Rodrigo et al., 2010). After the enamel and dentine are completely mature, ameloblasts degenerate into part of the reduced dental epithelium that covers and protects the surface of the enamel until tooth eruption, while odontoblasts persist in the dental pulp after tooth eruption (Kallenbach, 1970).

The epithelial-mesenchymal interactions that are critical to both salivary gland and tooth development are analogous in many ways (Denny et al., 1997), even though the morphological, anatomical and physiological features of the salivary glands differ greatly from those of the teeth during development. The major salivary glands not only develop at different sites and at different times, but also have very different structures and produce different types of saliva (Tucker, 2007). Most previous studies have been about the potential to promote development and the processes of tooth and salivary gland development, with an emphasis on the submandibular salivary gland; only a few studies have described the development of the parotid and sublingual
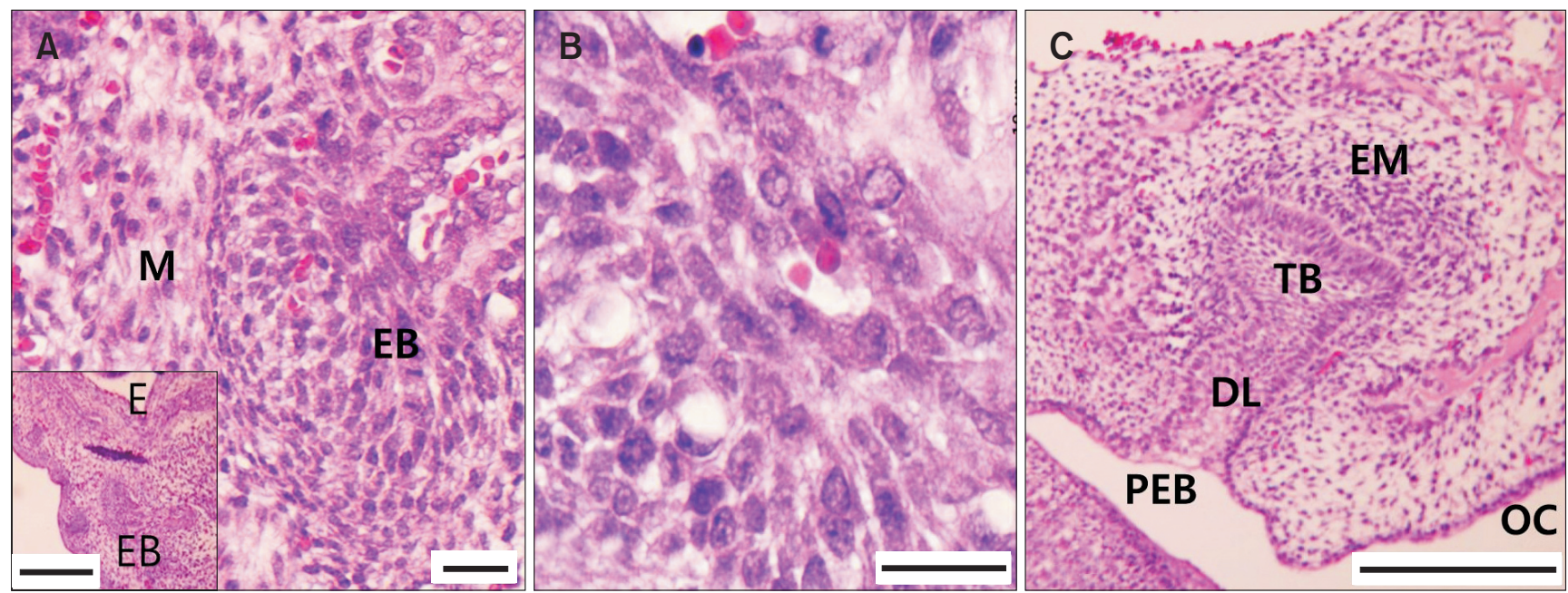

Fig. 1. Light micrographs of coronal section though the head at embryonic day 15 (E15). (A) Initial parotid salivary gland at the prebud stage showing a thickened epithelial bud (EB) growing into the mesenchyme (M). Inset: epithelial bud. (B) Higher magnification micrograph showing the epithelial bud forming a solid and condensed mass of homogenous cells. (C) Bud stage tooth showing the dental lamina (DL) and tooth bud (TB) from the primary epithelial band (PEB) growing into the ectomesenchyme. E, eye; OC, oral cavity. (A-C) H\&E stain. Scale bars=10 $\mu \mathrm{m}$ (inset), $1 \mu \mathrm{m}$ (A and B), $10 \mu \mathrm{m}$ (C).
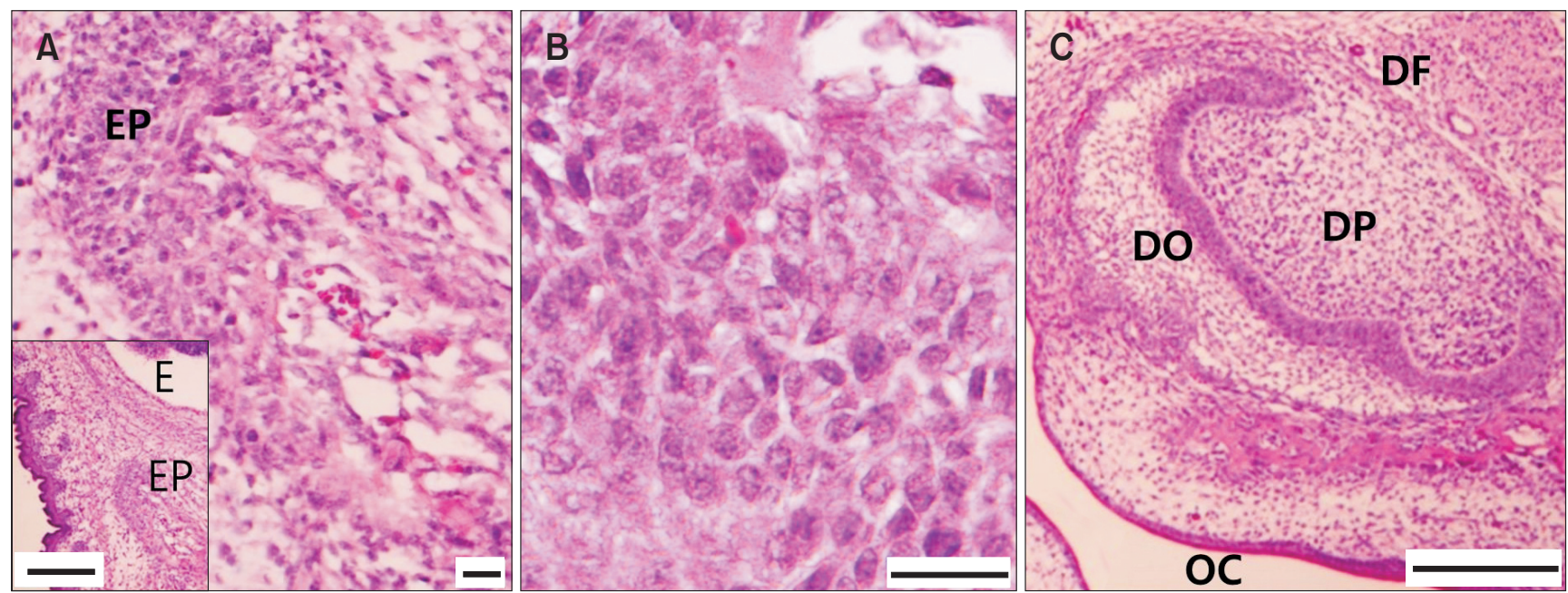

Fig. 2. Light micrographs of coronal section though the head at embryonic day 17 (E17). (A) Parotid salivary gland at the early initial bud stage showing the epithelial placode (EP). Inset: EP. (B) Higher magnification micrograph showing the EP with a solid mass of cells and a cord-like epithelial strand. (C) Cap stage tooth showing the dental organ (DO), dental papilla (DP) and dental follicle (DF). E, eye; OC, oral cavity. (A-C) H\&E stain. Scale bars=10 $\mu \mathrm{m}$ (inset), 1 $\mu \mathrm{m}$ (A and B), $10 \mu \mathrm{m}(\mathrm{C})$. 
salivary glands (Lui \& Wang, 2014; Rego et al., 2016; Varner \& Nelson, 2014). The reason for the differences in the developmental timing of the major salivary glands is still not well understood, nor is the relationship between the timing of parotid salivary gland and tooth development.

In the current study, we examined the prenatal and postnatal development of the mouse parotid salivary gland and tooth, and discuss the relationship between the developmental timing of these organs.

\section{MATERIALS AND METHODS}

Embryos from ICR outbred mice and mice from the Institute for Cancer Research (ICR, USA) were used in this study. All animal studies were approved by the "Institutional Animal Care and Use Committees" at Chosun University and animal care was carried out using the specific pathogen-free system according to the "Guide for the Care and Use of Laboratory Animals". Embryos at embryonic day 15 (E15), 17 (E17) and
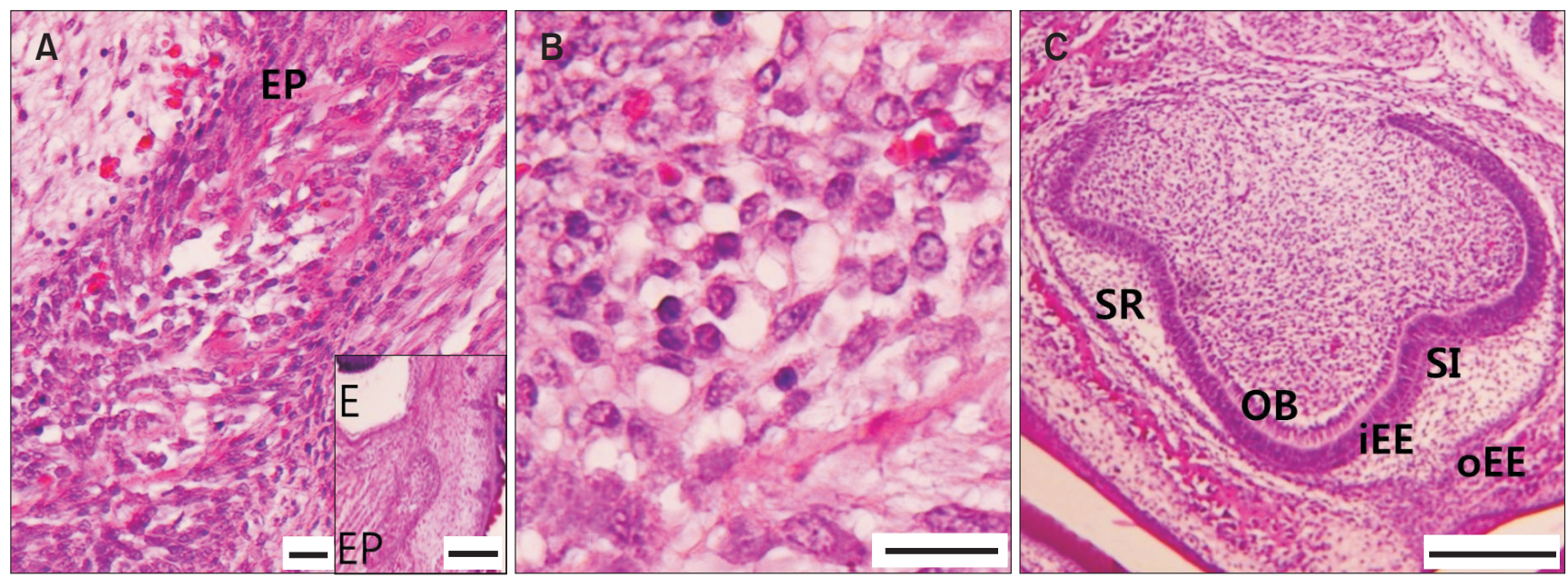

Fig. 3. Light micrographs of coronal section through the head at embryonic day 21 (E21). (A) Parotid salivary gland at the pseudoglandular stage showing the epithelial placode (EP). Inset: elongated and proliferated EP. (B) Higher magnification micrograph showing the EP with cubic and polygonal cells forming the ductal lumen. (C) Early bell stage tooth showing differentiated odontoblasts (OB), inner enamel epithelial cells (iEE), stratum intermedium (SI), stellate reticulum cells (SR), and outer enamel epithelial cells (oEE). E, eye. (A-C) H\&E stain. Scale bars=10 $\mu \mathrm{m}$ (inset), $1 \mu \mathrm{m}$ (A and B), $10 \mu \mathrm{m}$ (C).
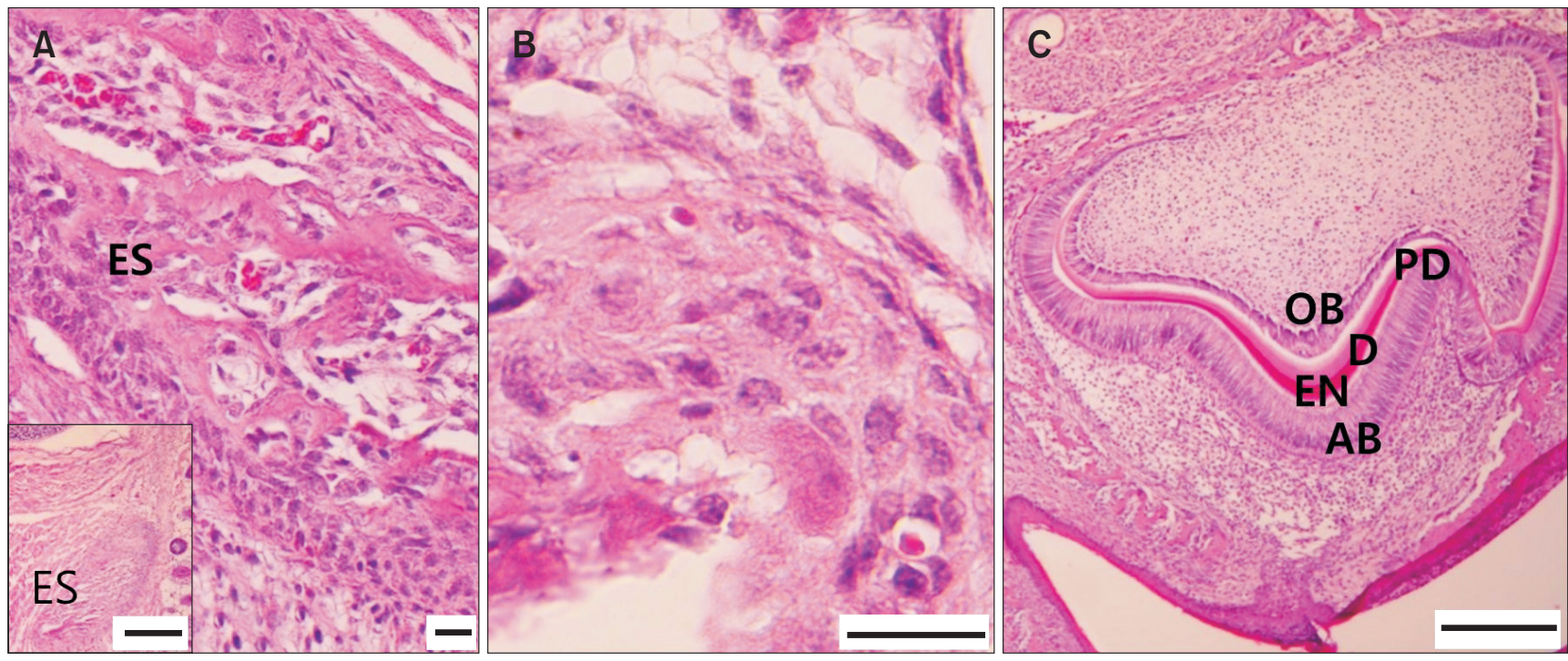

Fig. 4. Light micrographs of coronal section through the head at postnatal day 3 (PN3). (A) Parotid salivary gland at the pseudoglandular stage showing the epithelial stalk (ES) forming immature duct branches and terminated bulbs. Inset: large and more elongated ES. (B) Higher magnification micrograph showing the ES with flat cells at the base of the ductal lumen and columnar cells near the lumen. (C) Early advanced bell stage tooth showing enamel (EN) formed from secretory ameloblasts (AB) and dentine (D) formed from odontoblast (OB). PD, predentin. (A-C) H\&E stain. Scale bars=10 $\mu \mathrm{m}$ (inset), $1 \mu \mathrm{m}$ (A and $\mathrm{B}), 10 \mu \mathrm{m}(\mathrm{C})$. 
21 (E21) and mice at postnatal day 3 (PN3), 5 (PN5), 10 (PN10) and 21 (PN21) mice were used in the analysis. Mouse heads were fixed in ice cold $4 \%$ paraformaldehyde in phosphate buffer ( $\mathrm{pH}$ 7.2) for 12 hours. Tissues were then decalcified in $10 \%$ ethylenediaminetetraacetic acid (EDTA, $\mathrm{pH}$ 7.4) at $4^{\circ} \mathrm{C}$ for 4 weeks, dehydrated through a series of graded ethyl alcohol, then embedded in paraffin. Tissues were cut in sections of $6 \sim 7 \mu \mathrm{m}$ thickness and stained with $\mathrm{H} \& \mathrm{E}$. Stained sections were examined using a light microscope to evaluate the morphology and developmental stage.

\section{RESULTS}

\section{Prenatal Development of the Parotid Salivary Gland and Tooth}

\section{Embryonic day 15 (E15)}

At E15, the parotid salivary gland is at the prebud stage (Fig. 1A and inset). The developing gland was located at the connection between the maxillary and mandibular processes. A thickened epithelial bud had formed, and a solid condensed mass of homogenous cells could be seen growing into the surrounding mesenchyme (Fig. 1A and B). At the same stage, in the maxilla, the developing molar tissue is at the bud stage. The molar tooth bud and dental lamina could be seen growing into the ectomesenchyme from the primary epithelial band (Fig. 1C)

\section{Embryonic day 17 (E17)}

At E17, the developing parotid salivary gland is at the initial bud stage (Fig. 2A and inset). An epithelial placode could be observed, which consists of two parts: a solid mass of cells and a cord-like epithelial strand (Fig. 2A and B). At the same stage, in the maxilla, the developing molar tissues are at the cap sage, and consist of the dental organ, dental papilla, and dental follicle (Fig. 2C).

\section{Embryonic day 21 (E21)}

At E21, the parotid salivary gland is at the early pseudoglandular stage (Fig. 3A and inset). The epithelial placode is more elongated and has undergone some proliferation. The cord-like epithelial strand of the epithelial placode is beginning to make branches of ductal lumen with cubic and polygonal cells (Fig. 3B). At the same stage, the developing molar tissues are at the early bell stage. Outer enamel epithelial cells, stellate reticulum cells, stratum intermedium cells and inner enamel epithelial cells could be observed in the dental organ (Fig. 3C). The inner enamel epithelial cells adjacent to the dental papilla have begun to elongate and show characteristics of presecretory ameloblasts (Fig. 3C).

\section{Postnatal Development of the Parotid Salivary Gland and Tooth}

\section{Postnatal day 3 (PN3)}

At PN3 the parotid salivary gland is at of the late pseudoglandular stage (Fig. 4A and inset). The epithelial stalk was evident,
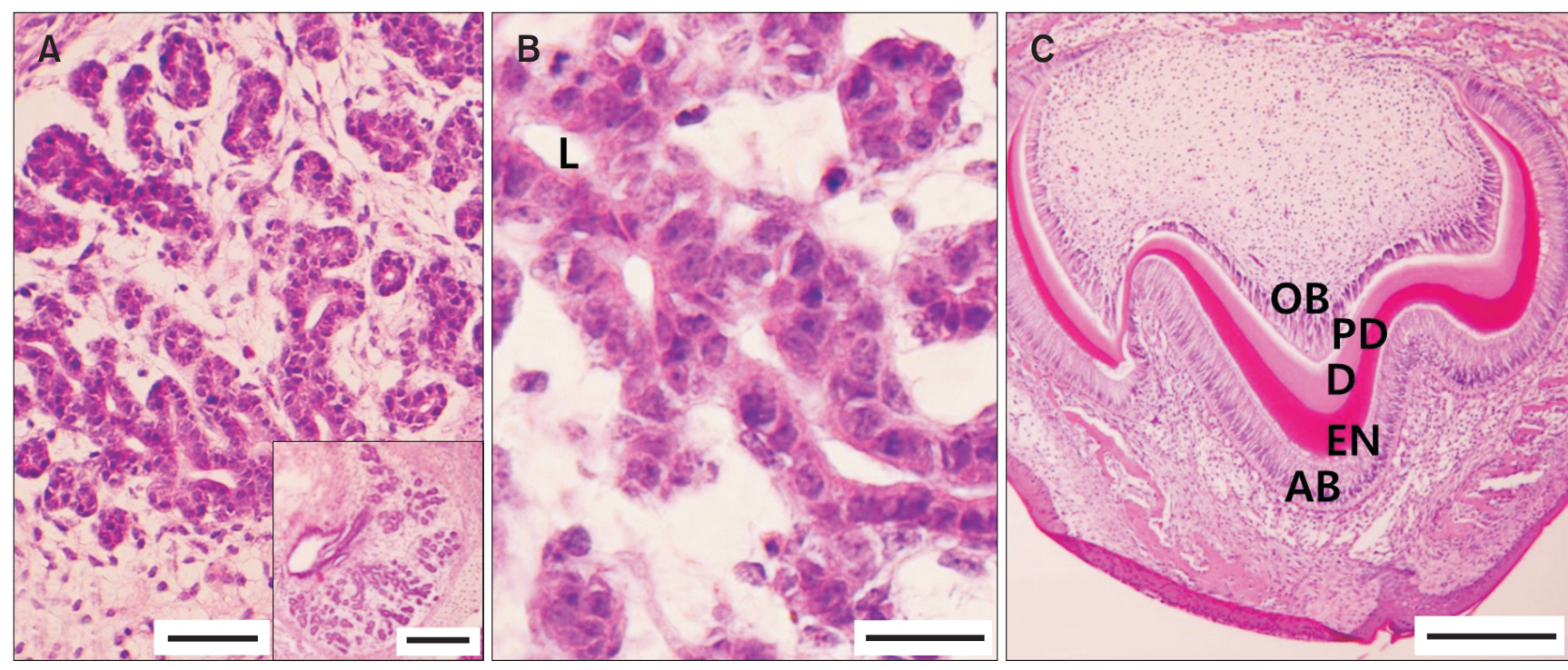

Fig. 5. Light micrographs of coronal section through the head at postnatal day 5 (PN5). (A) Parotid salivary gland at the canalicular stage showing an elongated and convoluted ductal structure and original acini at terminal epithelial buds. Inset: parotid salivary gland with ductral system and presumptive acini. (B) Higher magnification micrograph showing obvious lumenized main ducts, original acini and abundant loose connective tissue. (C) Late advanced bell stage tooth showing thick incomplete enamel (EN) and dentine (D). AB, ameloblast; L, lumen; OB, odontoblast; PD, predentin. (A-C) H\&E stain. Scale bars $=10 \mu \mathrm{m}$ (inset), $1 \mu \mathrm{m}$ (A and B), $10 \mu \mathrm{m}$ (C). 
and was beginning to form immature ductal branches, which terminated in a bulb (Fig. 4A and B). Homogeneous flat cells could be seen at the base of the ductal lumen, and columnar cells were present near the lumen (Fig. 4A). Several starshaped mesenchymal cells were present around the epithelial stalk (Fig. 4B). At the same sage, the developing molar tissues are at the early advanced bell stage. The structure was significantly elongated and contained an increased number of ameloblasts and odontoblasts. The enamel layer, formed from ameloblasts and the dentine and predentin layers, formed from odontoblasts could be observed (Fig. 4C). Secretory ameloblasts, which are long columnar cells with a nucleus on the basal side, had increased in number and were also more differentiated and elongated than at the earlier stages (Fig. 4C).

\section{Postnatal day 5 (PN5)}

At PN5, the parotid salivary gland is at the early canalicular stage (Fig. 5A and inset). It comprises an elongated and convoluted ductal structure, original acini could be observed, and it was still completely immature. More obvious lumenized main ducts could be seen, which were made from columnar cells, original acini and abundant loose connective tissue (Fig. 5A and B). The parotid salivary gland duct system had begun to form and the number of original acini had increased. At the same stage, the developing molar tissues are at the late advanced bell stage. Thick, but incomplete, enamel and dentine layers were forming, and the predentin layer was a constant thickness (Fig. 5C). Secretory ameloblasts of the maxillary molar tissues had increased in number, and were more differentiated and elongated compared to those at PN 3
(Fig. 5C)

\section{Postnatal day 10 (PN10)}

At PN10, the parotid salivary gland is at the late canalicular stage (Fig. 6A and inset). Differentiated and mature main ducts and branches could be observed, and mature intercalated ducts with a narrow lumen and glandular and conical acini cells could also be seen. There was an increase in the number and size of granular acini cells and lobuli, and a significant reduction in loose ectomesenchymal connective tissue around the acini (Fig. 6B). At the same stage, the molar tissues are at the crown stage. The tooth at this stage had thicker enamel and dentine layers (Fig. 6C). Secretory ameloblasts had changed to maturation stage ameloblasts, which had degenerated into part of the reduced dental epithelium (Fig. 6C).

\section{Postnatal day 21 (PN21)}

At PN21, the parotid salivary gland is at the terminal bud stage, and consisted of a complete, mature duct system with more obvious acini (Fig. 7A and inset). The lobules were still large, and the number and size of acini had increased even more. The intercalated ducts had secretory granules in the wide lumen, and acinar cells with numerous light-stained lucent granules were present (Fig. 7A and B). At the same stage, the molar tissues are at the functional stage; functional tooth had erupted into the oral cavity (Fig. 7C).

\section{DISCUSSION}

The salivary glands and teeth are classical model for the
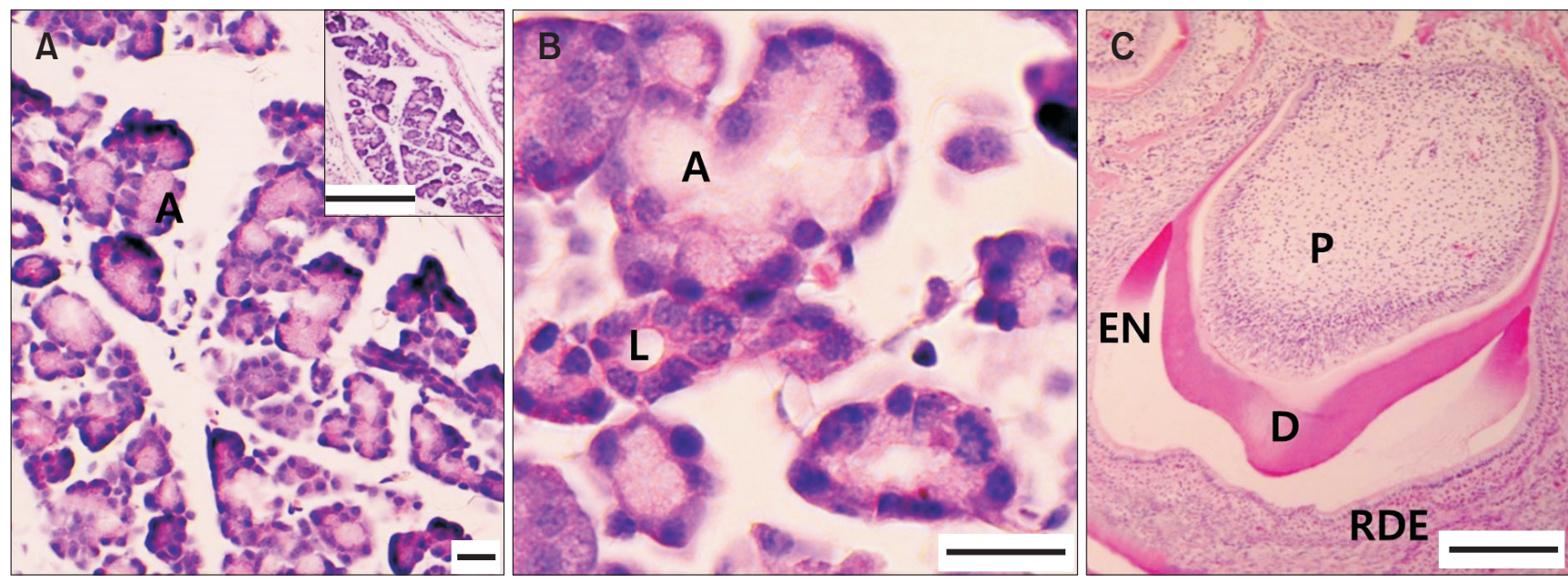

Fig. 6. Light micrographs of coronal section through the head at postnatal day 10 (PN10). (A) Parotid salivary gland at the canalicular stage showing a differentiated and immature main duct, some branching, and more obvious acini (A). Inset: parotid salivary gland with an immature duct system and acini undergoing maturation. (B) Higher magnification micrograph showing an increase in the number and size of glandular and conical acini cells and a significant reduction in loose connective tissue. (C) Crown stage tooth with thicker enamel (EN) and dentine (D). L, lumen; P, pulp; RED, reduced enamel epithelium. (A-C) H\&E stain. Scale bars=10 $\mu \mathrm{m}$ (inset), $1 \mu \mathrm{m}$ (A and B), $10 \mu \mathrm{m}$ (C). 

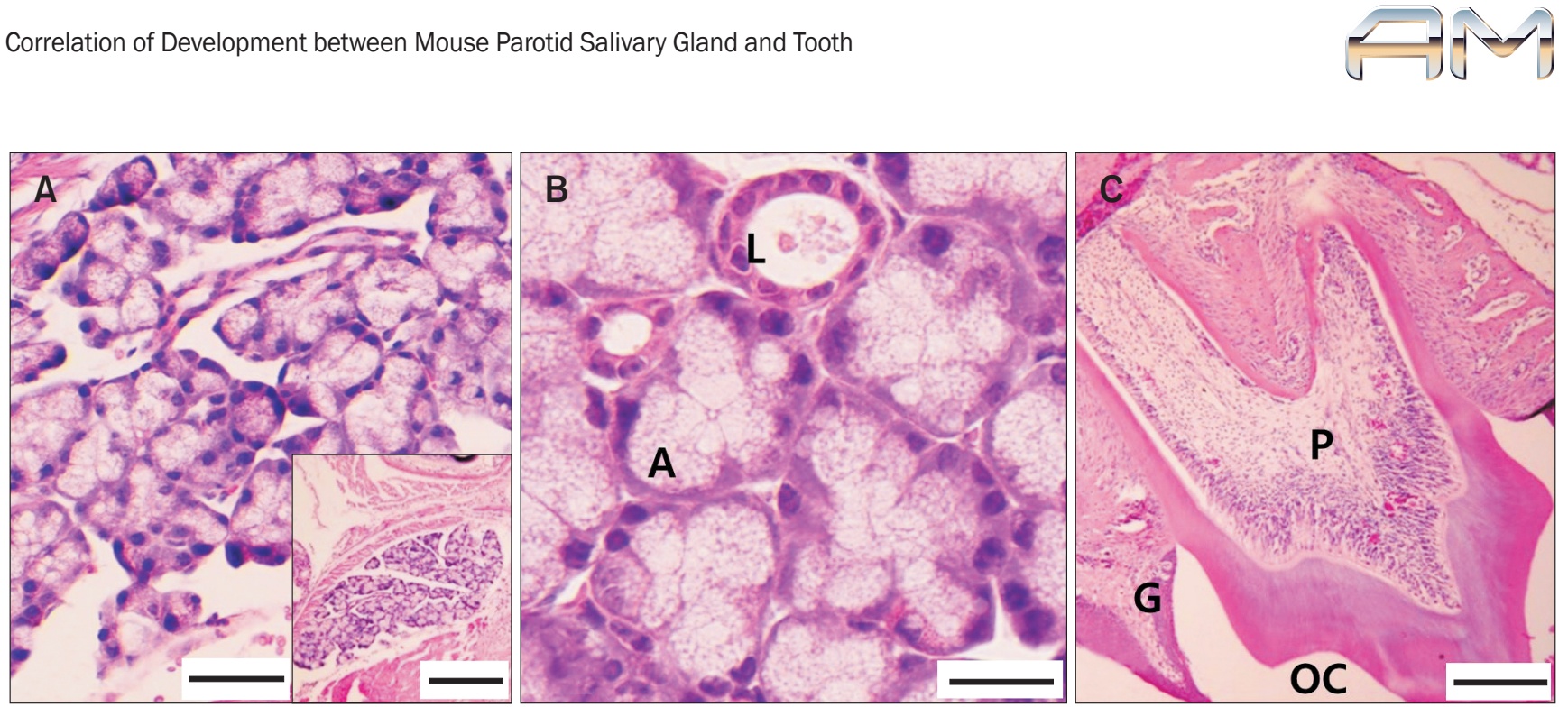

Fig. 7. Light micrographs of coronal section through the head at postnatal day 21 (PN21). (A) Parotid salivary gland at the terminal bud stage showing a complete and mature duct system and more obvious acini. Inset: complete parotid salivary gland. (B) Higher magnification micrograph showing wide lumen (L) of the intercalated ducts with secreted granules tightly packed with light stained lucent granules and increase in acinar cells. (C) Erupted functional stage tooth in the oral cavity (OC). A, acini; G, gingiva; P, pulp. (A-C) H\&E stain. Scale bars=10 $\mu \mathrm{m}$ (inset), $1 \mu \mathrm{m}$ (A and B), $10 \mu \mathrm{m}$ (C).

studying epithelial mesenchymal interactions during development (Denny et al., 1997; Tucker, 2007; Zhou et al., 2010). The mouse salivary gland is comprised of ducts, which terminate in lumen-containing acini that produce secretory granules (Ball, 1974; Cutler \& Gremski, 1991; Denny et al., 1997; Jaskoll et al., 1998; Melnick \& Jaskoll, 2000), while the tooth is composed of enamel, dentine, dental pulp and cement (Antonio, 2008). During development, the processes of cell proliferation, differentiation and apoptosis are mediated by specific molecules such as growth factors, cytokines and transcription factors, which are expressed at specific times and in specific locations (Hardman et al., 1994; Jaskoll \& Melnick, 1999; Kashimata \& Gresik, 1997; Kashimata et al., 2000a, 2000b; Melnick et al., 2001; Rego et al., 2016; Tucker, 2007). However, little is known about the identity of these molecules (Rego et al., 2016; Tucker, 2007).

In the present study, we characterized the development of mouse parotid salivary gland, which consists of five developmental stages, as suggested by Jaskoll et al. (1998): prebud, initial bud, pseudoglandular, canalicular, and terminal bud. The mouse parotid salivary gland begins its development on E15, which is the prebud stage. The primitive epithelial bud grows into the surrounding mesenchyme to form a solid epithelial placode on E17, the initial bud stage. The elongated and proliferated epithelial placode then begins to branch from E21 to PN3, the pseudoglandular stage, and eventually canalize to create a lumen between PN5 and PN10, which represents the canalicular stage. The majority of the ducts develop a lumen at the canalicular stage. The acini complete the lumenization process and have secretory granules at PN21, the terminal bud stage.

Development of the maxillary molar can be divided into the bud stage, cap stage, bell stage, crown stage and functional stage (Antonio, 2008). At E15, the developing molar tissue shows characteristics of the bud stage, with the formation of a tooth bud. E17 shows characteristics of the cap stage having formed the dental organ, dental papilla and dental follicle, and E21 is the early bell stage, when presecretory ameloblasts are present. PN3 to PN5 is the advanced bell stage, when the enamel layer is formed by ameloblasts and the dentine layers by odontoblasts, both of which have thickened by PN10, the crown stage. At PN21, the functional stage, the tooth has erupted into the oral cavity. Therefore, development of mouse parotid salivary glands and tooth are completed through a complex process of prenatal and postnatal morphogenesis (Fig. 8). These results are consistent with those from previous reports (Larsen et al., 2010; Leith et al., 2014; Melnick \& Jaskoll, 2000; Redman, 1988; Riberiro et al., 2006), with slight differences in the timing of some of the details (Larsen et al., 2010; Leith et al., 2014; Ogawa et al., 2013; Okumura et al., 2012; Rego et al., 2016; Tucker, 2007). Of all the major salivary glands, the sublingual salivary gland is the first to form and development is already complete at birth (Chi, 1996; Poulsen et al., 1986; Redman, 1988). The submandibular and parotid salivary glands develop in a similar timeframe, although the submandibular salivary gland becomes fully developed slightly before the parotid gland (Chi, 1996; Larsen et al., 2010; Zhou et al., 2010) and forms a more organized structure than the parotid gland (Leith et al., 2014). However, there are conflicting reports about the details of the development of the salivary glands, and there are few reports on the mouse parotid salivary gland (Riberiro et al., 2006). From our study, the development of the mouse parotid salivary gland is complete and becomes functional at about the same time as 
A

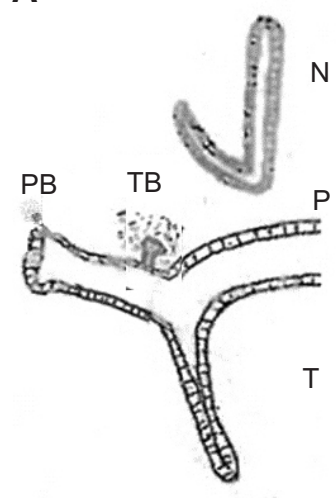

B

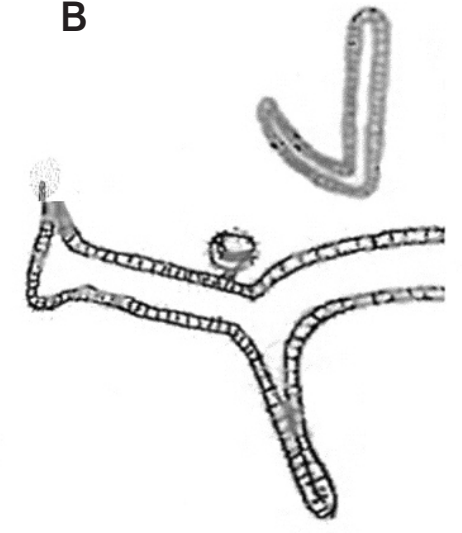

C

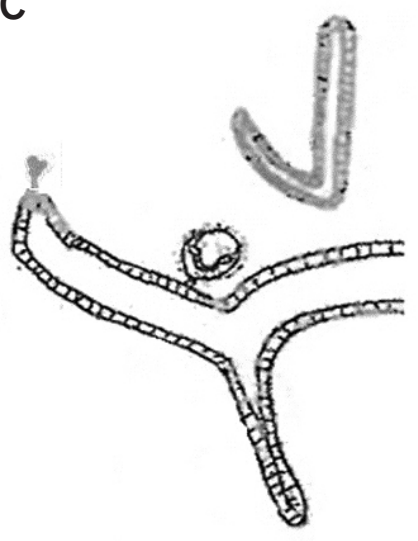

D

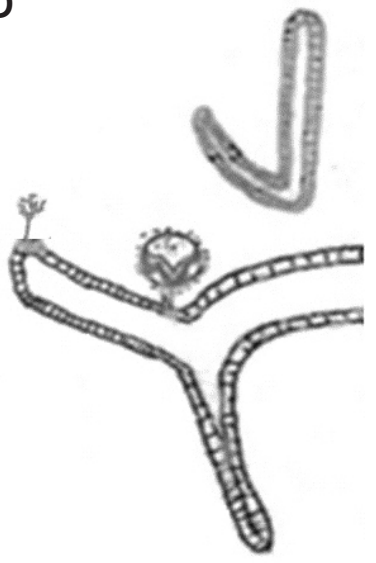

E

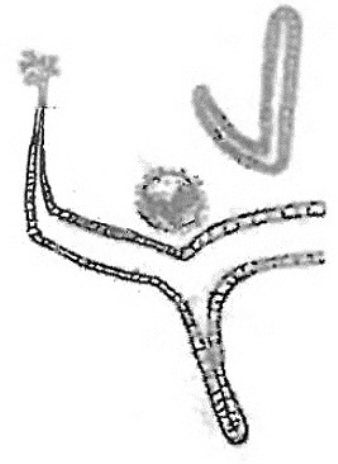

$\mathrm{F}$

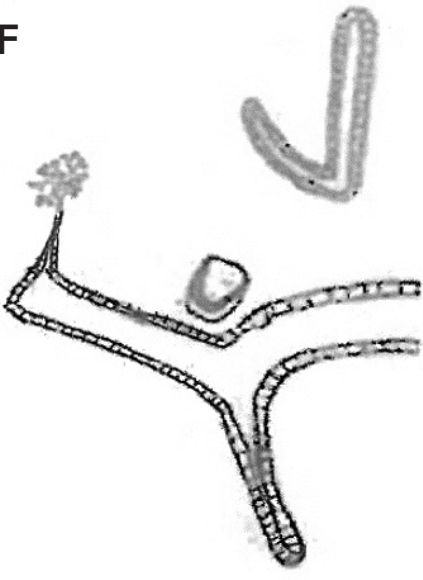

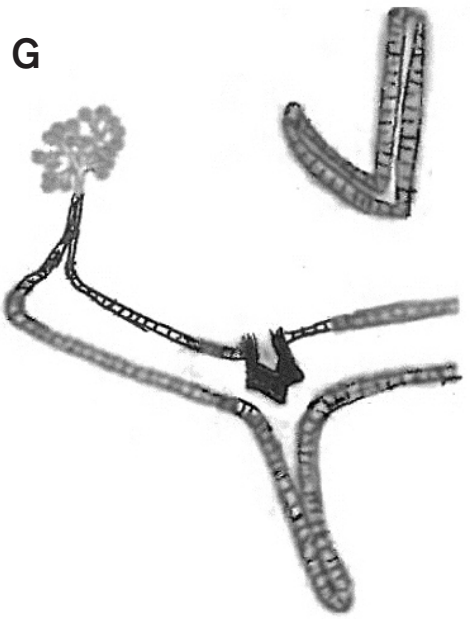

Fig. 8. Schematic diagram of parotid salivary gland and tooth development. (A) embryonic day 15 (E15), (B) E17, (C) E21, (D) postnatal day 3 (PN3), (E) PN5, (F) PN10, (G) PN21. N, nasal septum; P, palatal shelf; PB, parotid bud; T, tongue; TB, tooth bud.

that of the tooth development. This is different from the other major salivary glands. It is thought that complete formation of the parotid salivary gland is associated with the production and accumulation of secretory proteins in the acini at the final stage of postnatal development (Denny et al., 1997; Lawson, 1972; Leith et al., 2014; Redman \& Sreebny, 1970). Important genetic changes can be observed during this period, which are consistent with the above results (Denny et al., 1997; Poulsen et al., 1986). The reason for the differences in the start and completion time of development of the major salivary gland is unknown, but it is thought that the completion of parotid salivary gland development is similar to that of the tooth due to the secretory function of the parotid salivary gland. The parotid salivary gland produces serous saliva that contains large amounts of secretory proteins. Other salivary glands produce a constant amount of saliva, which is not a response to stimulation, but the parotid gland secretes large amounts of serous saliva following stimulation, for example after ingestion of food (Antonio, 2008). The proteins secreted by the parotid salivary gland are directly related to digestion (Antonio, 2008). In conclusion, our data show that the developmental completion time for both the parotid salivary gland and tooth is closely related to the weaning time of the animal, and suggest that this may be for functional reason.

\section{SUMIMARY}

Development of mouse parotid salivary gland begins on E15, which is the prebud stage; E17 is the initial bud stage; E21 to PN3 is the psedoglandular stage; PN5 to PN10 is the canalicular stage; and PN21 is the terminal bud stage. At E15, developing mouse maxillary molar is at the bud stage; at E17, it is at the cap stage; at E21, it is at the early bell stage; PN3 to PN5 comprises the advanced bell stage; at PN10, it is at the crown stage; at PN21, it is at the functional stage. Therefore, the development of mouse parotid salivary gland is completed through a process of prenatal and postnatal morphogenesis and becomes functional at about the same time as the 
developing tooth. The developmental completion times of the parotid salivary gland and tooth are closely related to the weaning time of animal for digestion.

\section{CONFLICT OF INTEREST}

No potential conflict of interest relevant to this article was reported.

\section{ACKNOWLEDGMENTS}

This work was supported by a 2017 research grant from Youngsan University, Republic of Korea.

\section{REFERENCES}

Amano 0 (2011) The salivary gland: anatomy for surgeons and researchers. Jap. J. Oral Maxillofac. Surg. 57, 384-393.

Amano O, Mizobe K, Bando Y, and Sakiyama K (2012) Anatomy and histology of rodent and human major salivary glands-Overview of the Japan salivary gland society-sponsored workshop. Acta Histochem. Cytochem. 45, 241-250.

Antonio N (2008) Salivary glands. In: Ten Cate's Oral Histology, Development, Streucture and Function, 7th ed. ed. Antonio N, pp. 290-318, (Elsevier, St. Louis).

Ball W D (1974) Development of the rat salivary glands. III. Mesenchymal specificity in the morphogenesis of the embryonic submaxillary and sublingual glands of the rat. J. Exp. Zool. 188, 277-288.

Chi J G (1996) Prenatal development of human major salivary glands. Histological and immunohistochemical characteristics with reference to dault and neoplastic salivary glands. J. Korean Med. Sci. 11, 203216.

Cutler L S and Gremski W (1991) Epithelial-mesenchymal interactions in the development of salivary glands. Crit. Rev. Oral Med. 2, 1-12.

Denny PC, Ball WD, and Redman RS (1997) Salivary glands: a paradigm for diversity of gland development. Crit. Rev. Oral Biol. Med. 8, 51-75.

Hardman P, Landels E, Woolfe A, and Spooner B (1994) TGF-beta inhibits growth and branching morphogenesis in embryonic mouse submandibular and sublingual glands in vitro. Dev. Growth Diff. 36, 567-577.

Jaskoll T, Chen H, Denny P, Denny P, and Melnick M (1998) Mouse submandibular gland mucin: embryo-specific mRNA and protein species. Mech. Dev. 74, 179-183.

Jaskoll T and Melnick M (1999) Submandibular gland morphogenesis: stage-specific expression of TGF-alpha, EGF, TGF-beta, TNF and IL-6 signal transduction in normal mice and the phenotypic effects of TGF-beta2, TGF-beta3, and EGF-R null mutaions. Anat. Rec. 256, 252-268.

Larsen M, Yamada K M, and Musselmann K (2010) Systems analysis of salivary gland development and disease. Rev. Syst. Biol. Med. 2, 670-682.

Lawson K A (1972) The role of mesenchyme in the morphogenesis and functional differentiation of rat salivary epithelium. J. Embryol. Exp. Morphol. 27, 497-513.

Leith N J, Nelson J W, Mellas R E, McCall A D, and Baker O J (2014) Threedimensional cultures of mouse submandibular and parotid glands: a comparative study. J. Tissue Eng. Regen. Med. doi: 10.1002/ term.1952.

Lui F and Wang S (2014) Moleculra cues for development and regeneration of salivary glands. Histol. Histopathol. 29, 305-312.

Kallenbach E (1970) Fine structure of rat incisor enamel organ during late pigmentation and regression stages. J. Ultrastruct. Res. 30, 3863.

Kashimata M and Gresik E (1997) Epidermal growth factor system is a physiological regulator of development of the mouse fetal submandibular gland and regulates expression of the $\alpha 6$-integrin subunit. Develop. Dyn. 208, 149-161.

Kashimata M, Sayeed S, Ka A, Onetti-Muda A, Sakagami H, Faraggiana T, and Gresik E W (2000a) The ERK-1/2 signaling pathway is involved in the stimulation of branching morphogenesis of fetal mouse submandibular glands by EGF. Dev. Biol. 220, 183-196.

Kashimata M W, Sakagami H W, and Gresik E W (2000b) Intracellular signaling cascades activated by the EGF receptor and/or intgrins, with potential relevance for branching morphogenesis of the fetal mouse submandibular gland. Eur. J. Morphol. 38, 269-275.

Maas R and Bei M (1997) The genetic control of early tooth development. Crit. Rev. Oral Biol. Med. 8, 4-39.

Melnick M, Chen H, Zhou Y M, and Jaskoll T (2001) Embryonic mouse submandibular salivary gland morphogenesis and the TNF/TNF-R1 signal transduction pathway. Anat. Rec. 262, 318-320.

Melnick M and Jaskoll T (2000) Mouse submandibular gland morphogenesis: a paradigm for embryonic signal processing. Crit. Rev. Oral Biol. 11, 199-215.

Ogawa M, Oshima M, Imamura A, Sekine Y, Ishida K, Yamashita K, Nakajima K, Hirayama M, Tachikawa T, and Tsuji T (2013) Functional salivary gland regeneration by transplantation of a bioengineered organ germ. Nat. Commun. doi: 10.1038/ncomms3498.

Okumura K, Shinohara M, and Endo F (2012) Capability of tissue stem cells to organize into salivary rudiments. Stem Cells Int. doi: $10.1155 / 2012 / 502136$.

Poulsen K, Jakobsen B K, Mikkelsen B M, Harmark Kim, Nielsen J T, and Hjorth J P (1986) Coordination of murine parotid secretory protein and salivary amylase expression. EMBO. J. 5, 1891-1896.

Redman R S (1988) Development of the salivary glands. In: The Salivary System, ed. Sreebny L M, pp. 1-20, (CRC Press, Boca Raton, FL).

Redman R S and Sreebny L M (1970) The prenatal phase of the morphosis of the rat parotid gland. Anat. Rec. 168, 127-138.

Rego M J, Silva Filho A F, Sobral A P, and Beltrao E I (2016) Glycomic profile of the human parotid gland between 18th and 26th week of fetal development. J. Oral Sci. 58, 353-360.

Riberiro T T, Sottovia A D, Cestari T M, and Taga R (2006) Morphometric 
study of the postnatal growth of the parotid gland of the mouse. Braz. Oral Res. 20, 13-20.

Rodrigo S L, Nanci A, Kurtz I, Wright J T, and Paine M L (2010) Regulation of pH During amelogenesis. Calcif. Tissue Int. 86, 91-103.

Saracco C G and Crabill E V (1993) Anatomy of the human salivary glands. In: Biology of the Salivary Glands, ed. Dobrosielski-Vergona K, pp. 1-14, (CRC Press, Boca Raton, FL).

Theslef I and Sharpe P (1997) Signaling networks regulating denta development. Mech. Dev. 67, 111-123.
Tucker A S (2007) Salivary gland development. Semin. Cell Cev. Biol. 18 237-244.

Varner V D and Nelson C M (2014) Cellular and physical mechanisms of branching morphogenesis. Development 141, 2750-2756.

Williams P L, Warwick R, Dyson M, and Bannister L H (1989) Gray's Anatomy. 37th ed. pp. 1290-1298, (Churchill Livingstone, Edinburgh).

Zhou J, Wang H, Tang G, Wang X, Sun Y, Song T, Zhang C, and Wang S (2010) Histological and ultrastructural characterization of developing miniature pig salivary glands. Anat. Rec. 293, 1227-1239. 